\title{
The effect of prostate weight on the outcomes of robot-assisted radical prostatectomy
}

\author{
Uğur Boylu, Turgay Turan, Cem Başataç, Fikret Fatih Önol, Eyüp Gümüş
}

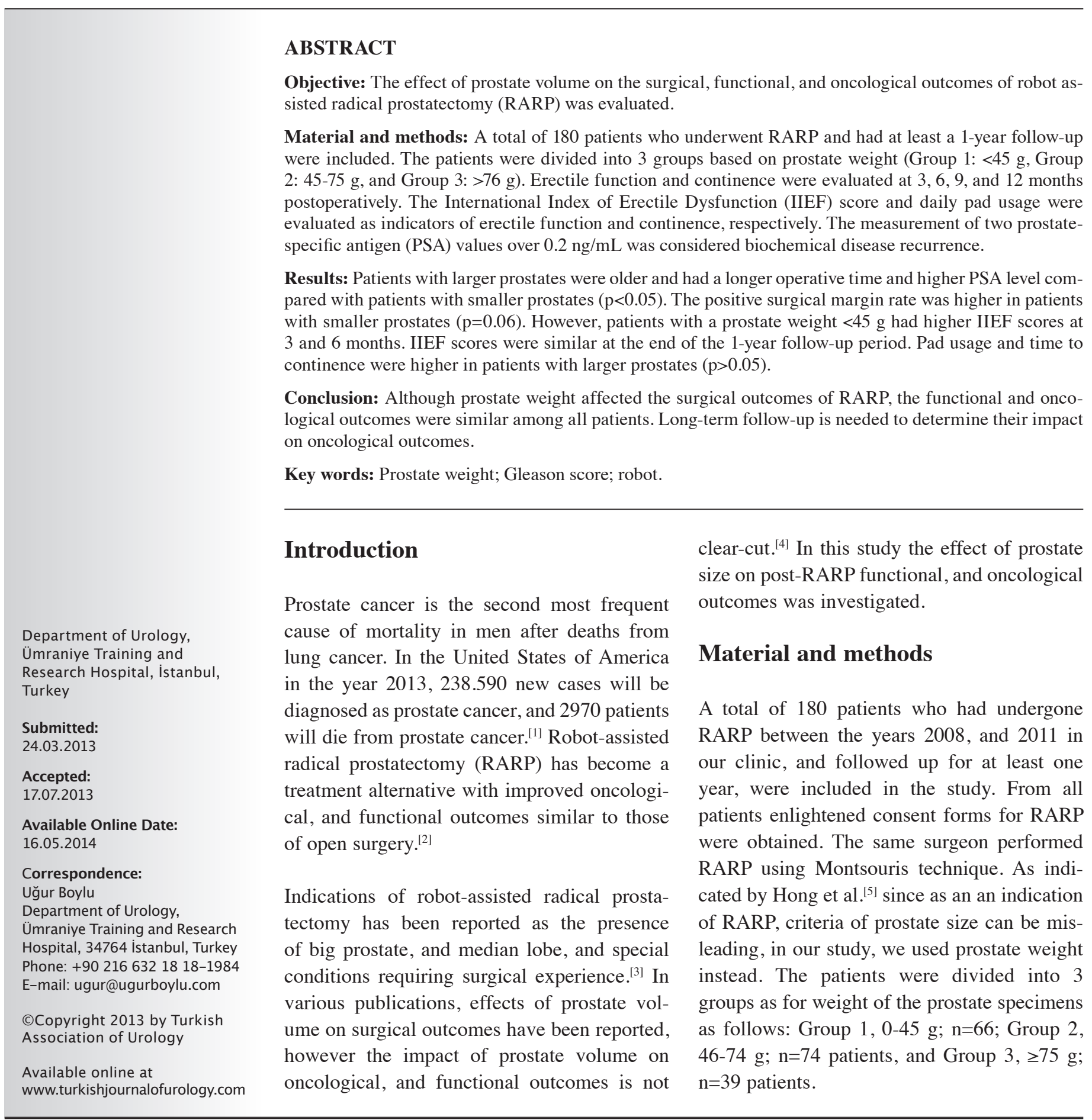


Erectile functions, and continence status were evaluated at 3 ., 6.99. and 12. months For the evaluation of erectile function International Index of Erectile Function (IIEF-5) was used. In case of detection of postoperative erectile dysfunction in preoperatively potent patients, the patients were randomized into two groups as those receiving 5-phosphodiesterase inhibitor or using vacuum device, and included in the penile rehabilitation protocol. For the evaluation of continence, number of daily pad use was recorded. Patients who didn't use pads or those using safety pads were considered as continent. Biochemical recurrence was considered as the detection of two successive PSA values over $0.2 \mathrm{ng} / \mathrm{mL}$ after the lowest prostate- specific antigen (PSA) value. The patients who received adjuvant therapy were not included in the study.

\section{Statistical analysis}

For the comparison of the parameters demonstrating normal distribution, One-way ANOVA test was used. For the comparison of parameters demonstrating non-normality distribution Kruskal- Wallis test, and for the determination of the group which was responsible for intergroup difference Mann-Whitney $\mathrm{U}$ test were used. For the comparison of qualitative data chisquare test was applied. Statistical significance was evaluated at $\mathrm{p}<0.01$, and $\mathrm{p}<0.05$, respectively.

\section{Results}

Median age of the patients was 62.9 (49-77 yrs) years. Median prostate weight of all the patients was 56.7 (10-260 g) g. Ages, operative times, preoperative PSA levels of the patients in Group 3 were found to be higher when compared with those found in Group 1 ( $\mathrm{p}<0.05)$. However, higher number of patients in Group 1 had positive surgical margins wth any statistically significant intergroup difference $(\mathrm{p}=0.06)$. Surgical characteristics of the patients according to their prostate volumes were summarized in Table 1.

Biochemical recurrence rates for the first year were 13.6, 9.3, and $5.1 \%$ for Groups1, 2, and 3, respectively. Any statistically significant intergroup difference was not detected $(\mathrm{p}=0.36)$ (Table 1). Groups were included in a multivariate analysis where factors effective on biochemical factors including clinical stage, PSA level, surgical margin positivity, Gleason score, and prostate volume were evaluated,. Surgical margin positivity (odds ratio: 6.16 [1.84-20.56], $\mathrm{p}=0.003$ ), preoperative PSA value (odds ratio: 1.07 [1.00-1.15], $\mathrm{p}=0.045$ ) were determined as independent risk factors. Prostate volume had no effect on biochemical recurrence.

IIEF scores of the patients during follow up period are given in Table 2. Preoperative potencies of the patients were similar $(\mathrm{p}=0.18)$, while in Group 1, IIEF scores were $5.95(\mathrm{p}=0.005)$ and $8.74(\mathrm{p}=0.016)$ at $1 ., 3$., and 6. month controls, respectively. These IIEF scores were found to be higher than those of the other two groups. However at the end of the first year, comparable IIEF-5 scores were 12.88, 11.16, and 9.38 for groups 1,2, and 3 , respectively $(p=0.20)$. At 12 . months of the follow-up period, mutivariate analysis performed evaluated factors that might effect potency including age, nerve-sparing surgery, and prostate volume. As demonstrated in multivariate analysis prostate volume did not effect IIEF-5 scores. Relatively smaller age of the patients $(\mathrm{p}=0.0001)$, and bilateral nerve-sparing surgery $(\mathrm{p}=0.042)$ had a favorable impact on potency.

\section{Table 1. Surgical, and oncological outcomes}

\begin{tabular}{|c|c|c|c|c|}
\hline & $\begin{array}{c}<45 g \\
(n=66) \\
\text { Group } 1\end{array}$ & $\begin{array}{c}\text { 46-75 g } \\
(n=75) \\
\text { Group } 2\end{array}$ & $\begin{array}{c}(\mathrm{n}=39) \\
>76 \mathrm{~g} \\
\text { Group } 3\end{array}$ & $\mathbf{p}$ \\
\hline Age (year) & 61.2 & 63.1 & 65.3 & 0.003 \\
\hline BMI $\left(\mathrm{kg} / \mathrm{m}^{2}\right)$ & 27.4 & 26.4 & 27.3 & 0.111 \\
\hline PSA (ng/mL) & 6.57 & 8.40 & 10.41 & 0.007 \\
\hline Biopsy Gleason Score & 6.17 & 6.29 & 6.08 & 0.099 \\
\hline Tumor volumes (\%) & 2.55 & 2.85 & 3.97 & 0.521 \\
\hline \multicolumn{5}{|l|}{ Clinical Stage (n, \%) } \\
\hline 1 & $39(59.1 \%)$ & $46(61.3 \%)$ & $20(51.3 \%)$ & \\
\hline 2 & $26(39.4 \%)$ & $26(34.7 \%)$ & $18(46.2 \%)$ & 0.714 \\
\hline 3 & $1(1.5 \%)$ & $3(4.0 \%)$ & $1(2.6 \%)$ & \\
\hline Operative time (mins) & 148.9 & 145.8 & 167.7 & 0.005 \\
\hline Amount of blood loss (mL) & 150 & 161 & 183 & 0.290 \\
\hline Hospital stay (days) & 3.80 & 3.85 & 3.90 & 0.085 \\
\hline Drain dwelling time (days) & 2.53 & 2.45 & 2.54 & 0.893 \\
\hline \multicolumn{5}{|l|}{ Nerve sparing (n, \%) } \\
\hline Not spared & $7(10.6 \%)$ & $15(20.0 \%)$ & $8(20.5 \%)$ & 0.209 \\
\hline Unilateral & $3(4.5 \%)$ & $7(9.3 \%)$ & $5(12.8 \%)$ & \\
\hline Bilateral & $56(84.8 \%)$ & $53(70.7 \%)$ & $26(66.7 \%)$ & \\
\hline $\begin{array}{l}\text { Positive surgical margin } \\
(\mathrm{n}, \%)\end{array}$ & $13(19.7 \%)$ & $6(8.0 \%)$ & $3(7.7 \%)$ & 0.066 \\
\hline Pathological Gleason Score & 6.29 & 6.64 & 6.26 & 0.292 \\
\hline \multicolumn{5}{|l|}{ Pathological Stage n (\%) } \\
\hline pT0 & $1(1.5 \%)$ & $1(1.3 \%)$ & $0(0 \%)$ & \\
\hline $\mathrm{pT} 2 \mathrm{a}$ & $6(9.1 \%)$ & $7(9.3 \%)$ & $13(33.3 \%)$ & \\
\hline $\mathrm{pT} 2 \mathrm{~b}$ & $0(0 \%)$ & $1(1.3 \%)$ & $0(0 \%)$ & \\
\hline pT2c & $44(66.7 \%)$ & $39(52 \%)$ & $18(46.2 \%)$ & \\
\hline pT3a & $12(18.2 \%)$ & $24(32 \%)$ & $7(17.9 \%)$ & \\
\hline pT3b & $3(4.5 \%)$ & $3(4.0 \%)$ & $1(2.6 \%)$ & \\
\hline $\begin{array}{l}\text { Biochemical recurrence } \\
(\mathrm{n}, \%)\end{array}$ & $9(13.6 \%)$ & $7(9.3 \%)$ & $2(5.1 \%)$ & 0.361 \\
\hline
\end{tabular}


Average number of pads used by the patients based on their prostate volumes, and their continence status are shown in Tables 3, and 4. Mean number of pads used daily by the patients were comparable (in Groups 1, 2, and 3, 0.21, 0.17, and 0.46 pads, respectively $(\mathrm{p}=0.547)$. Still at the end of 12 . months,comparable rates of continence in Groups 1, 2, and 3 were $90.9,89.3$, and $84.6 \%$, respectively $(\mathrm{p}=0.60)$. Although number of pads used in Group 3, and time to achieve continence were comparatively increased, it wasn't at a significant level $(\mathrm{p}>0.05)$.

\section{Discussion}

Nowadays, together with oncological success, improvement in functional complications including urinary incontinence, and erectile dysfunction constitute corner stones of the treatment. Therefore the factors except for PSA, Gleason score, clinical stage, and nevre sparing surgery which might effect these outcomes have been investigated in the literature. In various studies the impact of prostate volume on prostate surgery has been investigated, and larger prostate volume has been held responsible for prolonged operative times, and increased amount of bleeding. ${ }^{[6-8]}$

Min et al. ${ }^{[9]}$ reported that higher rates of surgical margin positivity were seen in patients with lower prostate volume who had undergone retropubic radical prostatectomies (RRP). However, they published their outcomes indicating that prostate volume

Table 2. IIEF-5 scores of the patients according to postoperative prostate volumes

\begin{tabular}{|c|c|c|c|c|}
\hline & $\begin{array}{c}<45 \mathrm{~g} \\
(\mathrm{n}=66)\end{array}$ & $\begin{array}{c}\begin{array}{c}46-75 \\
(n=75)\end{array} \\
\text { Group } 2\end{array}$ & $\begin{array}{c}>76 \mathrm{~g} \\
(\mathrm{n}=39) \\
\text { Group } 3\end{array}$ & $\underset{\text { value }}{p}$ \\
\hline Pre-op IIEF-5 score & 18.76 & 16.31 & 14.15 & 0.188 \\
\hline 3. IIEF-5 score & 5.95 & 4.37 & 3.13 & 0.005 \\
\hline 6. IIEF-5 score & 8.74 & 6.67 & 5.36 & 0.016 \\
\hline 9. IIEF-5 score & 10.61 & 9.04 & 7.77 & 0.242 \\
\hline 12. IIEF-5 score & 12.88 & 11.16 & 9.38 & 0.200 \\
\hline \multicolumn{5}{|c|}{ IIEF: International Index of Erectile Dysfunction } \\
\hline
\end{tabular}

\begin{tabular}{|c|c|c|c|c|}
\hline & $\begin{array}{c}<45 \mathrm{~g} \\
(\mathrm{n}=66)\end{array}$ & $\begin{array}{l}46-75 \mathrm{~g} \\
(\mathrm{n}=75)\end{array}$ & $\begin{array}{l}>76 \mathrm{~g} \\
(\mathrm{n}=39)\end{array}$ & $\begin{array}{c}p \\
\text { value }\end{array}$ \\
\hline & Group 1 & Group 2 & Group 3 & \\
\hline 3. postop. month & 1.17 & 1.09 & 1.47 & 0.361 \\
\hline 6. postop. month & 0.58 & 0.42 & 0.72 & 0.603 \\
\hline 9. postop. month & 0.33 & 0.24 & 0.64 & 0.245 \\
\hline 12. postop. month & 0.21 & 0.17 & 0.46 & 0.547 \\
\hline
\end{tabular}

less than $40 \mathrm{~g}$ is an independent risk factor for biochemical recurrence at 5 . month of the follow-up period Chang et al. ${ }^{[10]}$ allocated 400 patients on whom they had performed laparoscopic radical prostatectomy (LRP) into two groups based on their prostate volumes. Despite prolonged operative times in patients with prostate volumes greater than $75 \mathrm{~g}$, they found lower rates of surgical margin positivity. Similarly, Marchetti et al. ${ }^{[11]}$ reported the outcomes of their 690 patients who had undergone RRP, and indicated that lower prostate volume was associated with increased rates of surgical margin positivity. In our study, higher rates of surgical margin positivity in patients with lower prostate volumes relative to the other groups were not statistically significant ( $\mathrm{p}=0.066$ ). Our scarce number of patients compared to other literature studies might be the reason for the detection of these higher rates of positivity. Besides,any difference was not observed between biochemical recurrence rates estimated at 1 . postoperative years. In our multivariate analysis,PSA, and positive surgical margins were independent factors for biochemical recurrence, while prostate volumes were not. Gershman et al. ${ }^{[12]}$ reported that in patients with prostate volumes less than $40 \mathrm{cc}$, risk of upgrading Gleason score increased. This risk of erroneous grading might be one of the reasons for falsely increased rates of surgical margin positivity. Another reason for higher surgical margin positivity might be related to negligence to take prostate volume in D'Amico risk classification. Despite their inclusion in a lower risk group, patients with lower prostate volumes should be evaluated more precautiously.

Link et al. ${ }^{[13]}$ published outcomes of their patients who had undergone RPRP based on their prostate volumes, and couldn't find any difference between groups as for continence, and biochemical recurrence rates. In this study where erectile function was not included in the evaluations, the authors emphasized that in patients with larger prostates, robotic surgery can be applicable. Pettus et al. ${ }^{[14]}$ reported that prostate volumes of the patients who had undergone open or laparoscopic prostatectomies have no effect on the functional results at first years. Similarly Zorn et al. ${ }^{[15]}$ did not report any difference between rates of continence in patients who had under-

\begin{tabular}{|c|c|c|c|c|}
\hline & $\begin{array}{c}<45 \\
(n=66)\end{array}$ & $\begin{array}{c}46-74 \\
(n=75)\end{array}$ & $\begin{array}{c}>75 \\
(n=39)\end{array}$ & $\begin{array}{c}p \\
\text { value }\end{array}$ \\
\hline & Group 1 & Group 2 & Group 3 & \\
\hline 3. postop. month & $33(50.0 \%)$ & $33(44.0 \%)$ & $13(33.3 \%)$ & 0.251 \\
\hline 6. postop. month & $48(72.7 \%)$ & $58(77.3 \%)$ & $28(71.8 \%)$ & 0.750 \\
\hline 9. postop. month & $66(84.8 \%)$ & $66(88.0 \%)$ & $30(76.9 \%)$ & 0.300 \\
\hline 12. postop. month & $60(90.9 \%)$ & $67(89.3 \%)$ & $33(84.6 \%)$ & 0.604 \\
\hline
\end{tabular}


gone RARP. However, Meeks et al. ${ }^{[16]}$ emphasized that median lobe prolongs óperative time without any effect on continence rates. Only Konety et al. ${ }^{[17]}$ reported that patients with larger prostates had gained their continence much later than other BPH patients. Since in their study, instead of prostate volume, only results of the transrectal measurements were used which might not give a true estimate of the prostate gland. Montorsi et al. ${ }^{[3]}$ published the results of Pasadena consensus panel, and reported that the presence of median lobe complicates surgical intervention which requires experienced surgeons. It was indicated that to gain sufficient experience, 40 operations should be performed annually. They pointed to the presence of advanced age, obesity, and a larger prostate gland as risk factors for the development of incontinence. Similarly, in our study, we couldn't observe any difference between groups as for prostate volume, and time to achieve continence.

Labanaris et al. ${ }^{[4]}$, performed RARP on their patients, and published functional comparative outcomes of these patients based on their prostate weights ( $>100 \mathrm{~g}$ or $<50 \mathrm{~g}$ ) In this study erectile scores of the patients were evaluated using IIEF scores. The patients with preoperative erectile dysfunction, and those who hadn't undergone interfascial nerve sparing surgery were not included in the study. At the end of 12. months, rate of potency was 61.9 in patients with larger prostates, while in the group with smaller prostates it was reported as $72.9 \%$ which was statistically significant $(\mathrm{p}<0.05)$. In our study, any difference was not observed between erectile functions at first years, while IIEF-5 scores at 3., and 6. months were higher in patients with lower prostate volumes. When IIEF -5 scores at 12 . months were evaluated in a multivariate analysis, advanced age, failure to perform nerve-sparing surgery decreased IIEF-5 scores, while prostate volume did not effect potency. Zorn et al. ${ }^{[15]}$ could not find any difference as for time to achieve baseline erectile function. In this study, authors reported that the impact of prostate volume on erectile function was not clear-cut. Still in Pasedena consensus panel, importance of the impact of preoperative condition of the patient, and postoperative rehabilitation on erectile function was underlined. Besides, avoidance of using thermal energy near neurovascular bundle during operation, and minimal use of traction were also recommended.

In conclusion, though size of the prostate effected surgical outcomes of the patients who had undergone RARP, it didn't exert any impact on the first year functional, and oncological outcomes. For the determination of oncological impact, further studies with longer follow-up periods are required.

Informed Consent: Written informed consent was obtained from patients who participated in this study.

Peer-review: Externally peer-reviewed.
Author Contributions: Concept - U.B., T.T., C.B., F.F.Ö., E.G.; Design - U.B., T.T., C.B., F.F.Ö., E.G.; Supervision - U.B., E.G.; Funding - U.B., E.G.; Materials - U.B., E.G.; Data Collection and/ or Processing - U.B., T.T., C.B., F.F.Ö., E.G.; Analysis and/or Interpretation - U.B., E.G.; Literature Review - U.B., E.G.; Writer U.B., T.T.; Critical Review - U.B., E.G.

Conflict of Interest: No conflict of interest was declared by the authors.

Financial Disclosure: The authors declared that this study has received no financial support.

\section{References}

1. Siegel R, Naishadham D, Jemal A. Cancer statistics, 2013. CA Cancer J Clin 2013;63:11-30.

2. Boylu U, Başataç C, Turgay T, Önol FF, Gümüş E. Robot-assisted reduce prostatectomy: Its surgical, oncological, and functional outcomes. Turkish Journal of Urology 2012;38:8-13.

3. Montorsi F, Wilson TG, Rosen RC, Ahlering TE, Artibani W, Carrol PR, et al. Best practices in robot-assisted radical prostatectomy: recommendations of the Pasadena Consensus Panel. Eur Urol 2012;62:368-81.

4. Labanaris AP, Zugor V, Witt JH. Robot-assisted radical prostatectomy in patients with a pathologic prostate specimen weight $\geq 100$ grams versus $\leq 50$ grams: surgical, oncologic and short-term functional outcomes. Urol Int 2013;90:24-30.

5. Hong MK, Yao HH, Rzetelski-West K, Namdarian B, Pedersen J, Peters JS, et al. Prostate weight is the preferred measure of prostate size in radical prostatectomy cohorts. BJU Int 2012;109:57-63.

6. Hsu EI, Hong EK, Lepor H. Influence of body weight and prostate volume on intraoperative, perioperative, and postoperative outcomes after radical retropubic prostatectomy. Urology 2003;61:601-6.

7. Singh A, Fagin R, Shah G, Shekarriz B. Impact of prostate size and body mass index on perioperative morbidity after laparoscopic radical prostatectomy. J Urol 2005;173:552-4.

8. Boczko J, Erturk E, Golijanin D, Madeb R, Patel H, Joseph JV. Impact of prostate size in robot-assisted radical prostatectomy. $\mathrm{J}$ Endourol 2007;21:184-8.

9. Min SH, Park YH, Lee SB, Ku JH, Kwak C, Kim HH. Impact of prostate size on pathologic outcomes and prognosis after radical prostatectomy. Korean J Urol 2012;53:463-6.

10. Chang CM, Moon D, Gianduzzo TR, Eden CG. The impact of prostate size in laparoscopic radical prostatectomy. Eur Urol 2005;48:285-90.

11. Marchetti PE, Shikanov S, Razmaria AA, Zagaja GP, Shalhav AL. Impact of prostate weight on probability of positive surgical margins in patients with low-risk prostate cancer after robotic-assisted laparoscopic radical prostatectomy. Urology 2011;77:677-81.

12. Gershman B, Dahl DM, Olumi AF, Young RH, Scott McDougal $\mathrm{W}, \mathrm{Wu} \mathrm{CL}$. Smaller prostate gland size and older age predict Gleason score upgrading. Urol Oncol 2011 Dec 27. [Epub ahead of print]. 
13. Link BA, Nelson R, Josephson DY, Yoshida JS, Crocitto LE, Kawachi $\mathrm{MH}$, et al. The impact of prostate gland weight in robot assisted laparoscopic radical prostatectomy. J Urol 2008;180:92832.

14. Pettus JA, Masterson T, Sokol A, Cronin AM, Savage C, Sandhu JS, et al. Prostate size is associated with surgical difficulty but not functional outcome at 1 year after radical prostatectomy. J Urol 2009;182:949-55.

15. Zorn KC, Orvieto MA, Mikhail AA, Gofrit ON, Lin S, Schaeffer AJ, et al. Effect of prostate weight on operative and postoperative outcomes of robotic-assisted laparoscopic prostatectomy. Urology 2007;69:300-5.

16. Meeks JJ, Zhao L, Greco KA, Macejko A, Nadler RB. Impact of prostate median lobe anatomy on robotic-assisted laparoscopic prostatectomy. Urology 2009;73:323-7.

17. Konety BR, Sadetsky N, Carroll PR; CaPSURE Investigators. Recovery of urinary continence following radical prostatectomy: the impact of prostate volume--analysis of data from the CaPSURE Database. J Urol 2007;177:1423-6. 